\title{
Factors affecting Chinese university students' intention to continue using virtual and remote labs
}

Mu-Hua Zhang

National Engineering Laboratory for Cyberlearning and Intelligent Technology, Faculty of Education, Beijing Normal University, Beijing, China

Chien-Yuan Su

Department of Curriculum and Learning Sciences, College of Education, Zhejiang University, Hangzhou, China

Yan Li

Research Center for AI in Education, Department of Curriculum and Learning Sciences, College of Education, Zhejiang University, Hangzhou, China

\section{Yan-Yan Li}

Smart Learning Institute, Faculty of Education, Beijing Normal University, Beijing, China

Recently, virtual and remote labs (VRLs) have been developed to support students in conducting experiments in engineering and science education. However, little is known about the students' intentions to continue using VRLs and their satisfaction with the experience. This study proposed an extended model embedded within the expectation confirmation model and two variables concerning flow experience (time distortion and focused attention) to predict Chinese university students' satisfaction with and intention to continue using VRLs. A structural equation modelling technique based on covariance was conducted to evaluate survey questionnaire responses received from 238 students at a university located in central China. The results demonstrated that satisfaction was the most crucial determinant of the students' intention to continue using VRLs, followed closely by perceived usefulness. Confirmation played an indirect role in predicting students' intentions to continue using VRLs via satisfaction and perceived usefulness. Students' flow experience while performing virtual experiments played a positive and direct role in confirming their expectations of VRLs.

Implications for practice or policy:

- Instructors and higher education institutions could improve students' satisfaction with VRL-based experimental teaching and increase their intention to continue using VRLs in their future studies by providing them with optimal flow experiences.

- Designers and developers could improve the quality of these VRLs from the perspective of the users' flow experience.

- Researchers could verify more factors that influence confirmation and clarify how they could be manipulated in future studies.

Keywords: intention to continue using, satisfaction, expectation confirmation model, flow experience, virtual and remote labs

\section{Introduction}

Providing students with hands-on opportunities to conduct experiments is essential in engineering and science education (Heradio et al., 2016). With the continued progress of information and communication technologies (ICTs), a number of virtual and remote labs (VRLs) supported by different technologies, such as sensor-augmented virtual labs (Chao, Chiu, DeJaegher, \& Pan, 2016), virtual labs equipped with immersive virtual reality (Makransky, Terkildsen, \& Mayer, 2019), virtual labs equipped with mobile mixed reality (Birt, Stromberga, Cowling, \& Moro, 2018; Moro, Stromberga, \& Stirling, 2017), and international manufacturing remote labs (Grodotzki, Ortelt, \& Tekkaya, 2018), have been successfully developed and have the potential to promote better experimental operation experiences in e-learning contexts (Heradio et al., 2016; Tho \& Yeung, 2016). For example, learners can access the physical equipment in the real world via the Internet and distantly manipulate this equipment through the interface 
of an experiment in remote labs and they can conduct the experiments with simulations using mono-user or multi-user modes in virtual labs. The application of the VRLs not only eliminates the limits of time and space but also has high flexibility, accessibility, repeatability, and safety (Alves, Viegas, Lima, \& Gustavsson, 2016). Moreover, learning materials or resources in VRLs could help schools that need to reuse materials and perhaps reduce the waste of resources in physical laboratories (Viegas et al., 2018). In general, some scaffolding or sophisticated learning design (e.g., removing confusing details and emphasising important information) (Nolen \& Koretsky, 2018) can be integrated into the experiment process in VRLs to facilitate students' understanding of sophisticated engineering or scientific concepts (Post, Guo, Saab, \& Admiraal, 2019) and to stimulate deeper learning (Viegas et al., 2018). According to empirical studies (Brinson, 2015; Faulconer \& Gruss, 2018; Vrellis, Avouris, \& Mikropoulos, 2016), student performance using virtual experiments is equal to, or better than, student performance using real experiments. Student performance includes inquiry skills (Tatli \& Ayas, 2013), practical skills (Hawkins \& Phelps, 2013), perception (Barbeau, Johnson, Gibson, \& Rogers, 2013), analytical skills (Pyatt \& Sims, 2012), and social and scientific communication (Lang, 2012).

However, all of the above expectations would come to nothing if students were not satisfied with this virtual and remote experimental operation and discontinue using it after its initial acceptance. Some studies have tried to investigate students' perceptions of using the VRLs. For example, Raman, Achuthan, Nedungadi, Diwakar, and Bose (2014) treated virtual labs as educational technology innovation and investigated potential adopters' perceptions of virtual labs based on the diffusion of innovation theory (Rogers, 2003). Liu, Yang, and Chan (2013) explored students' learning continuance in virtual worlds using the lenses of social constructivism (Vygotsky, 1986) and the balanced thinking-feelings model (Kim, Chan, \& Chan, 2007). Teng, Nedic, and Nafalski (2016) reported students' perceptions of a remote laboratory called NetLab through a self-reported survey. Estriegana, Medina-Merodio, and Barchino (2019) used Davis' (1989) technology acceptance model (TAM) to explore students' adoption of online learning environments that incorporate teaching videos, virtual laboratories, and interactive exercises. Although these studies paid attention to the students' perception of using VRLs, few have focused on students' satisfaction with and intention to continue using, from a post-acceptance perspective.

The expectation confirmation model (ECM) (Bhattacherjee, 2001) is a post-acceptance model concerning the motivations behind users' decisions to continue using information systems (IS) after their initial acceptance (Ambalov, 2018). The ECM has proven to be superior to other models (such as Davis' (1989) TAM) in predicting users' intentions to continue using a system (Halilovic \& Cicic, 2013). In addition, considering that students conduct experimental operations in a virtual environment, the characteristics of multimedia interaction may improve students' engagement and participation (Esteban-Millat, MartínezLópez, Huertas-García, Meseguer, \& Rodríguez-Ardura, 2014; Joo, Lim, \& Kim, 2012; Shin, 2006). A similar learning experience of learning by doing or experiential learning is related to flow (Qian \& Clark, 2016), which has been used to explain and predict users' satisfaction with multimedia learning (Cheng, 2014a; Guo, Xiao, Van Toorn, Lai, \& Seo, 2016; Kang \& Kim, 2018; Lee, 2010; Rodríguez-Ardura \& Meseguer-Artola, 2016).

Thus, this study attempted to examine the latent predictors of students' satisfaction with the VRL experience and the predictors of students' intention to continue using VRLs after their initial acceptance. By developing an integrated extended model that combines the ECM and flow theory, we strove to explain and predict university engineering students' perspectives in terms of satisfaction with and intention to continue using VRLs.

\section{Theoretical background}

\section{$E C M$}

Because users' expectations of technology may change after they have experienced it, Bhattacherjee (2001) proposed a theoretical framework, the ECM, which is based on the expectation confirmation theory (Oliver, 1980). The ECM is used to illustrate users' consciousness of the congruence between the actual performance of an IS and their expectation of using it. The ECM contains four post-consumption variables (see Figure 1): perceived usefulness, confirmation, satisfaction, and IS continuance intention (Leung \& Chen, 2019). Perceived usefulness describes users' perceptions of the benefits of using an IS. Confirmation refers to users' perceptions regarding the congruence between the actual performance of an IS and users' expectations of its usage. Satisfaction refers to users' emotions regarding prior IS usage. IS continuous 
intention refers to users' intentions regarding continued usage of an IS. According to Bhattacherjee (2001), there are five relationship hypotheses grounded in this model. First, users' continuance intention to use an IS is positively associated not only with their level of satisfaction with initially using an IS but also with their perceived usefulness toward using an IS. Thus, users' satisfaction with using an IS is determined by the extent to which their expectations of IS use and their perceived usefulness of the initial IS use are confirmed. Finally, users' extent of confirmation has a positive influence on their perceived usefulness of IS use.

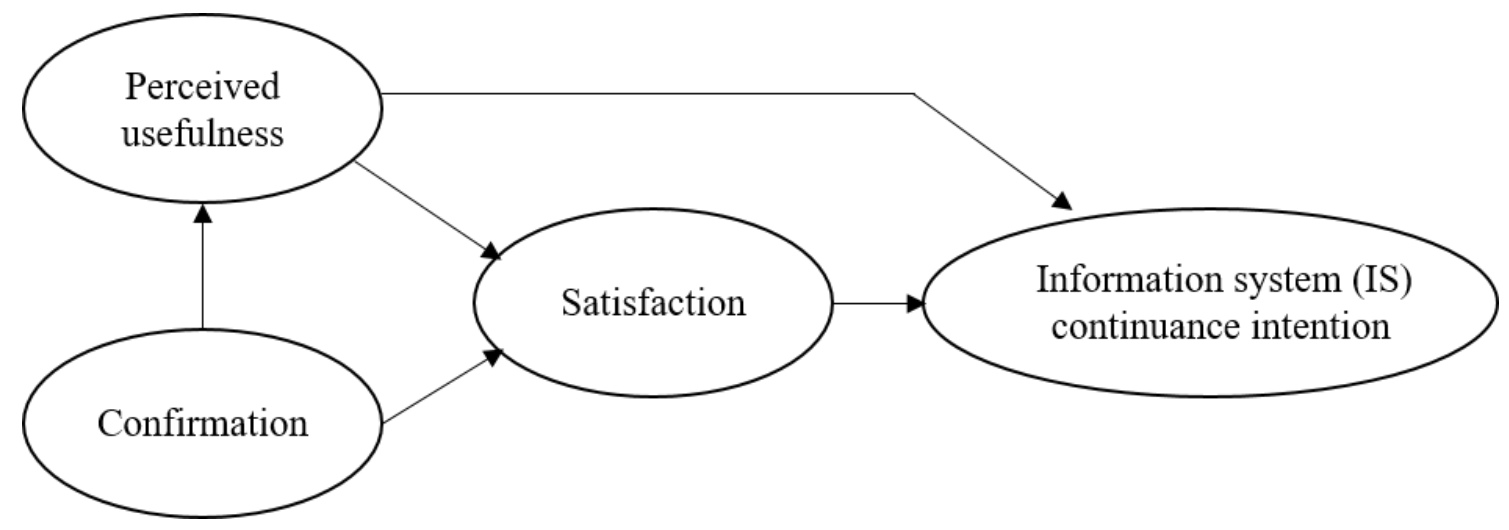

Figure 1. ECM (Bhattacherjee, 2001, p. 356)

Up until now, researchers have used the ECM to explore and explain users' intentions to continue using and behaviours towards continuing use in various contexts, such as mobile applications and web-based services (Malik \& Rao, 2019), social network sites (Ambalov, 2018), online reviews (Vijay, Prashar, \& Gupta, 2018), and the e-health and m-health field (Leung \& Chen, 2019). In e-learning contexts, the ECM has also been used to explore and explain learners' intentions to continue employing e-learning systems or tools. For example, some scholars have used the ECM to investigate the perceptions of college students (Baker-Eveleth \& Stone, 2015) and high school students (Joo, Park, \& Shin, 2017) to continue using ebooks. Cheng (2014a) extended the ECM with factors related to quality (instructor, information, system, and support service) to investigate Taiwanese nurses' intention to continue using a blended e-learning system. Alraimi, Zo, and Ciganek (2015) proposed an extended ECM with perceived reputation and perceived openness to examine users' continued intention of using massive open online courses (MOOCs). Joo and Choi (2016) used an extended ECM to explore students' intentions to continue to use online library resources. Zhou (2017) extended the ECM with social influence, performance proficiency, and knowledge outcomes to investigate learners' intention to continue using MOOCs.

Some studies (Dağhan \& Akkoyunlu, 2016; Ho, 2010; Lee, 2010) have integrated the ECM and related models (e.g., Davis' (1989) TAM, Oliver's (1980) cognitive model, and Liao, Palvia, and Chen's (2009) technology continuance theory) to understand users' intentions towards continuing to use e-learning systems or tools. For example, Ho (2010) integrated TAM, the ECM, the self-determination model (Deci \& Ryan, 2000), and the cognitive model to explain and predict users' intention to continue to use the elearning platform, confirming that satisfaction and attitude had a significant and positive effect on users' continuance intention. Lee (2010) synthesised the TAM, ECM, the theory of planned behaviour (Ajzen, 1991), and flow theory (Csikszentmihalyi, 1990) to explore the factors affecting users' intention to continue to use e-learning, discovering that satisfaction was the most significant predictor of users' intentions to continue using e-learning, while perceived usefulness, perceived behaviour control, attitude, subjective norm, and concentration were significant but weaker predictors. Dağhan and Akkoyunlu (2016) integrated an IS's success model, cognitive model, the ECM, and technology continuance theory to understand the determinants of students' continuance intention to use online learning environments and found that satisfaction was the strongest predictor of their intention to continue to use, followed by perceived value, utilitarian value, and perceived usability. Overall, these studies have demonstrated that integrating the ECM with other related models or theories could reinforce an explanation of users' intentions or perspectives to continue to use e-learning systems or tools. 


\section{Flow theory}

Flow can be described as a psychology of optimal experience in which the individual's body or mind is stretched to its limits in a voluntary effort to accomplish something that is difficult or worthwhile and has a deep sense of enjoyment (Csikszentmihalyi, 1990). Csikszentmihalyi (2014) further defined nine dimensions of flow: (a) immediate feedback, (b) clear goals, (c) balance between skill and challenge, (d) merging of awareness and action, (e) sense of control, (f) concentration on tasks, (g) loss of selfconsciousness, (h) experience that becomes autotelic, and (i) time distortion. Among these nine dimensions, the first three are considered to be the inevitable prerequisites for flow to occur (Buil, Catalán, \& Martínez, 2018; Csikszentmihalyi, 2014); they describe the characteristics of tasks or activities an individual has undertaken. The remaining six elements are related to flow experience (Buil et al., 2018) and describe an individual's feelings when he/she is experiencing flow. Although the nine dimensions could be applied to assess flow experience or its condition, most studies have typically not adopted all these constructs, but just selected specific constructs to measure flow according to the context and purpose of their research (Buil et al., 2018). For example, Shin (2006) measured students' flow experience in a video-on-demand virtual course with five constructs: time distortion, focused attention, enjoyment, telepresence, and engagement. Lee (2010) synthesised two constructs of flow experience (perceived enjoyment and concentration) into the ECM, the TAM, and the theory of planned behaviour (Ajzen, 1991) to investigate university students' intention to continue using a web-based learning program for continuing education. Esteban-Millat et al. (2014) proposed a comprehensive model of flow that integrated four constructs - time distortion, focused attention, sense of control, and interactivity — to explore students' behavioural processes in virtual learning environments. Guo et al. (2016) investigated learners' flow experiences with three constructsconcentration on tasks, loss of self-consciousness, and time distortion-for an online course delivered through Blackboard. Chang, Warden, Liang, and Lin (2018) investigated students' flow experience in digital game-based learning with three constructs: engagement, enjoyment, and control. Matute-Vallejo and Melero-Polo (2019) examined students' flow experience in an online business simulation game of a marketing course in terms of three aspects: time distortion, focused attention, and self-perceptions of flow.

In research related to flow experience, time distortion (Chen, Wigand, \& Nilan, 2000; Kiili, 2005; Skadberg \& Kimmel, 2004) and focused attention (Esteban-Millat et al., 2014; Hoffman \& Novak, 1996; Novak, Hoffman, \& Yung, 2000; Shin, 2006; Skadberg \& Kimmel, 2004) were the two most frequently tested variables and were identified to positively affect students' flow experience when learning in a virtual environment (Esteban-Millat et al., 2014). The concept of time distortion is related to cognitive psychology; it was adopted by Novak et al. (2000) to survey users' flow experience in online environments. Time distortion is a phenomenon in which individuals lose track of time and feel like time is passing away at an abnormal rate (Esteban-Millat et al., 2014). Due to the integration of various advanced technologies and the creation of virtual environments, students may easily feel that they are travelling across time and space while experiencing VRLs. Focused attention was also found to be like concentration, which was first used by Trevino and Webster (1992) to measure users' flow in computer-mediated communication. Focused attention means that individuals focus their attention on a narrow stimulus field and remove irrelevant perceptions and thoughts (Webster, Trevino, \& Ryan, 1993). While experiencing VRLs, challenging tasks, and the computer-mediated virtual environment may narrow students' attention to a specific stimulus field and lead to flow experience. Therefore, this study adopted time distortion and focused attention as predictors to explore university students' flow experiences in VRL contexts.

\section{Research model and hypotheses}

Grounded in the ECM (Bhattacherjee, 2001) and flow theory (Csikszentmihalyi, 1990), the study regarded two variables related to flow experience - time distortion and focused attention - as external variables that could explain and predict Chinese university students' satisfaction with and their continued intention in VRL usage. Figure 2 shows the hypothesised model proposed in our study. 


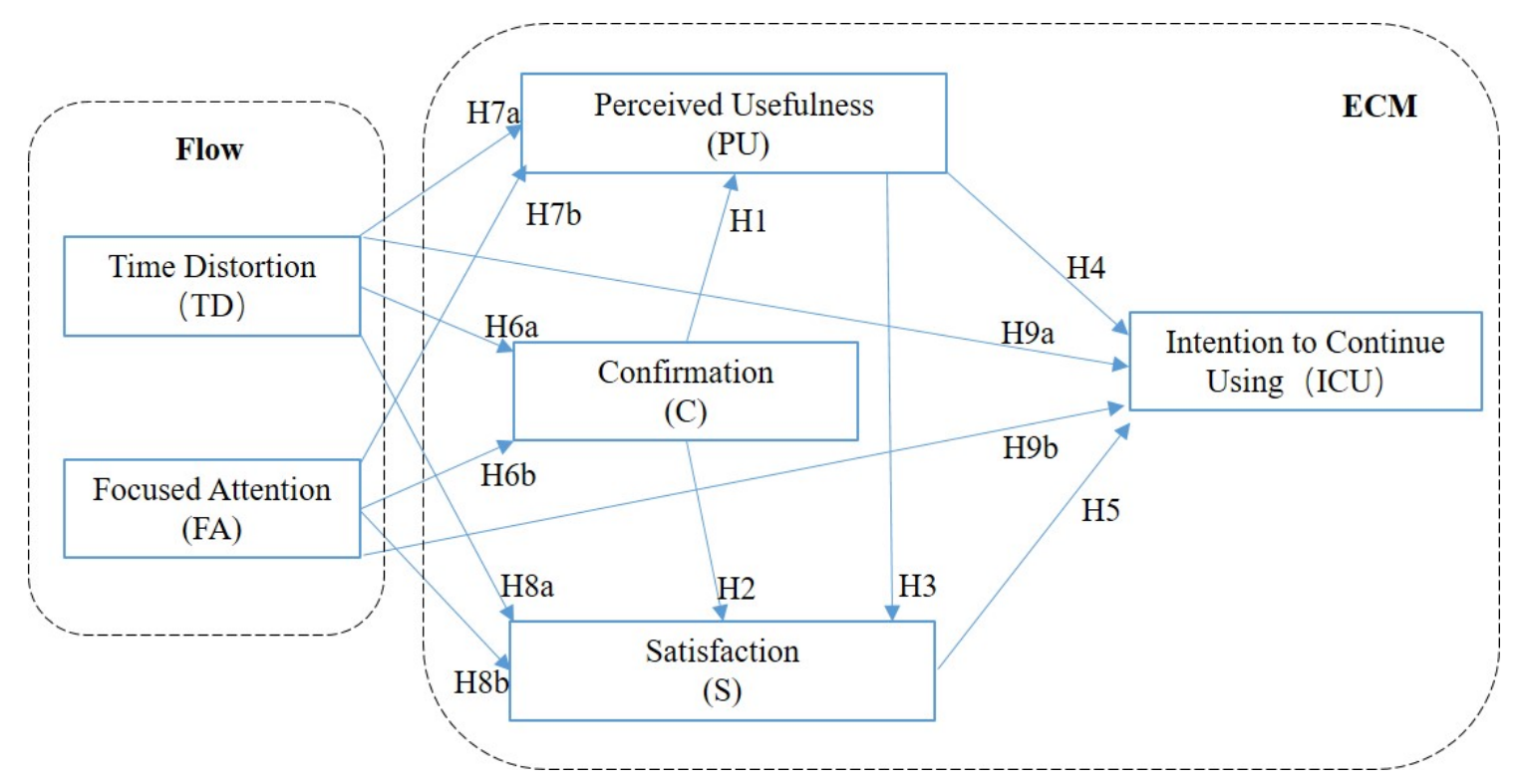

Figure 2. The research model

The following hypotheses were put forward in the study:

- H1: Confirmation positively affects students' perceived usefulness of VRLs.

- H2: Confirmation positively affects students' satisfaction with VRLs.

- H3: Perceived usefulness positively affects students' satisfaction with VRLs.

- H4: Perceived usefulness positively affects students' intention to continue using VRLs.

- H5: Satisfaction positively affects students' intention to continue using VRLs.

- H6a: Time distortion positively affects students' confirmation of VRLs.

- H6b: Focused attention positively affects students' confirmation of VRLs.

- H7a: Time distortion positively affects students' perceived usefulness of VRLs.

- H7b: Focused attention positively affects students' perceived usefulness of VRLs.

- H8a: Time distortion positively affects students' satisfaction with VRLs.

- H8b: Focused attention positively affects students' satisfaction with VRLs.

- H9a: Time distortion positively affects students' intention to continue using VRLs.

- H9b: Focused attention positively affects students' intention to continue using VRLs.

\section{Methodology}

\section{Participants and context}

The participants were undergraduates (aged 17 to 21 years) from science and technology-related departments at China Three Gorges University. Students who attended a required undergraduate course, "Introduction to Computer Science", participated in this study. All participants had the necessary computer skills and had not used this VRL platform. Before the survey, a written consent form was obtained from each of the participants before collecting the data. They were told that their participation was voluntary and their grade in the course would not be affected; in addition, all participating students were assured that their responses would remain strictly confidential and anonymous to avoid possible non-response bias. Since 30 students declined to respond, 240 students in total (mean age 18 years), consisting of 152 males (63.33\%) and 88 females (36.67\%), actually took part in the survey.

The experiment was carried out for a total of 8 weeks, for 2 hours per week. In the first week, students received an introduction to the learning platform operation to understand how many learning tasks would be performed in total. In the second to the eighth week, students were required to complete a virtual experiment activity with a particular topic and take the corresponding quiz that had been set in advance every week. Before each VRL experience activity, the instructor introduced the basic content of the experiment and gave simple experimental operation instructions to help students have a better experience. 
While each virtual experiment was being conducted by the students, the platform provided 10 operation limit prompts in order to avoid their casual operation through trial and error, as well as to give feedback to correct students' answers in each quiz. At the end of the experiment in Week 8, all students completed a questionnaire.

\section{Instruments}

A two-part questionnaire was created to investigate participants' satisfaction with VRLs and their continued intention to use them. In the first part of the questionnaire, questions regarding the participants' demographic information were included, such as age, gender, and terms. In the second part, 18 items were refined to measure the constructs in the proposed framework. The first six items were employed to investigate the students' flow experience in terms of two dimensions: focused attention and time distortion. The following 12 items were revised from Bhattacherjee's (2001) ECM scale, which contains four constructs: perceived usefulness, confirmation, satisfaction, and intention to continue using. To measure these items, we adopted a five-point Likert scale; the answer choices of each item ranged from 1 (strongly disagree) to 5 (strongly agree). Considering the research context was related to VRLs, all the items were slightly modified (e.g., replacing "ODB" with "VRLs") and were presented in Chinese. Furthermore, to keep the statements clear, appropriate, and easy to understand for the students, two experts in the educational technology field reviewed the modified items.

To validate the instrument, a pilot test was carried out with 30 university students (not participants in the study and who had used VRLs) through convenience sampling to discover any confusion in the instrument's wording and improve the layout if necessary. The reliability coefficients of all the constructs were calculated, and the items that had a low contribution to reliability were removed. Consequently, 16 items were administered to investigate the students' satisfaction with and their intention to continue using VRLs. Table 1 shows the items of the final questionnaire. The Cronbach's alpha values of all the constructs were between 0.78 and 0.91 , showing that the internal consistency of the survey items was sufficient.

Table 1

Constructs and items in the questionnaire

\begin{tabular}{|c|c|c|}
\hline Construct & Item & Source \\
\hline $\begin{array}{l}\text { Time } \\
\text { distortion } \\
\text { Focused } \\
\text { attention }\end{array}$ & $\begin{array}{l}\text { I often lose sense of time while experiencing VRLs. } \\
\text { I feel time passed so quickly while experiencing VRLs. } \\
\text { I feel I can concentrate when I experience VRLs. } \\
\text { I become addicted to the tasks at hand while experiencing VRLs. }\end{array}$ & $\begin{array}{l}\text { Esteban-Millat } \\
\text { et al. (2014, p. } \\
121)\end{array}$ \\
\hline $\begin{array}{l}\text { Perceived } \\
\text { usefulness }\end{array}$ & $\begin{array}{l}\text { I obtain the knowledge introduced in the course through } \\
\text { experiencing VRLs. } \\
\text { My knowledge increases through experiencing VRLs. } \\
\text { I feel that learning is going on when I experience VRLs. }\end{array}$ & \\
\hline Confirmation & $\begin{array}{l}\text { Support services embedded within VRLs are better than my } \\
\text { expectation. } \\
\text { Learning performance by using VRLs is better than my } \\
\text { expectation. } \\
\text { To a large extent, my expectations about experiencing VRLs were } \\
\text { confirmed. }\end{array}$ & $\begin{array}{l}\text { Bhattacherjee } \\
(2001, \text { p. } 370)\end{array}$ \\
\hline Satisfaction & $\begin{array}{l}\text { Overall, I feel very satisfied with the experience of VRLs. } \\
\text { Overall, I feel absolutely delighted when I experience VRLs. } \\
\text { Overall, I feel very contented when I experience VRLs. }\end{array}$ & \\
\hline $\begin{array}{l}\text { Intention to } \\
\text { continue using }\end{array}$ & $\begin{array}{l}\text { I am going to continue using VRLs rather than quit using them in } \\
\text { my future studies. } \\
\text { I intend to experience more types of VRLs in future studies. } \\
\text { I hope more opportunities will be provided for me to experience } \\
\text { VRLs in future studies. }\end{array}$ & \\
\hline
\end{tabular}




\section{Learning platform and teaching materials}

The learning platform Virtual Experiment Workshop (http://www.vrsygc.com/index), developed by the Beijing Institute of Technology, was selected to provide a VRL operational environment for students in this study. The platform offers multimedia teaching materials related to computer science topics, such as 3D models, interactive animation, sound, and video. It further provides some useful human-computer interaction (e.g., web pages with embedded $2 \mathrm{D}$ or $3 \mathrm{D}$ scenes) that enables students to immerse themselves and participate in experimental contexts and ensures that a large number of users can simultaneously perform a virtual experiment through the Internet. After registering and logging on to the website, users can experience VRLs by using a mouse and keyboard. According to usage statistics on the platform (http://www.vrsygc.com/xcourse/showcoulist), as of November 2019, there are approximately 150 colleges or universities in China that have adopted this platform to carry out related experimental teaching in computer science. Students and teachers can register with the platform and participate in or use open online experimental materials.

We conducted a course, "Introduction to Computer Science", on the platform and designed seven cases of virtual experiments with different difficulty levels to facilitate student learning. Two low-difficulty virtual experiments were used to promote students' understanding of operating procedures involved in computer hardwire assembly and disassembly and file management. Two virtual experiments with different difficulty levels (one experiment of medium difficulty and one of high difficulty) were provided to enhance students' comprehension of the essential science concepts of computer science, such as the Turing model and firewalls. The other three virtual experiments (two of medium difficulty and one of high difficulty) were used to help students understand the primary principles of computer science, including information conversion of Chinese characters and images on computers and executing instructions on a computer. Table 2 shows the virtual experiments involved in this study.

Table 2

Virtual experiments in the "Introduction to Computer Science" course

\begin{tabular}{|c|c|c|c|}
\hline Name & Type & $\begin{array}{l}\text { Technological } \\
\text { approach }\end{array}$ & $\begin{array}{l}\text { Difficulty } \\
\text { level of task }\end{array}$ \\
\hline $\begin{array}{l}\text { Assembling and disassembling computer } \\
\text { hardware }\end{array}$ & Demonstration & 3D display & Low \\
\hline Managing files on a computer & Authentication & 2D animation & Low \\
\hline Firewalls & Demonstration & 2D animation & Medium \\
\hline Turing model & Demonstration & 2D animation & High \\
\hline $\begin{array}{l}\text { Coding and storing Chinese characters on a } \\
\text { computer }\end{array}$ & Authentication & 2D animation & Medium \\
\hline Coding and storing images on a computer & Design & 2D animation & Medium \\
\hline Executing an instruction on a computer & Authentication & 2D animation & High \\
\hline
\end{tabular}

Firewall principle demonstration experiment, a unit of the virtual experiment we designed, is shown in Figure 3. First, when the students entered the section of this learning theme, the platform displayed the operating information for the virtual experiments, including purpose of the experiment, content, and operation tips (see Figure 3(a)). Students could use a mouse and keyboard to perform virtual experiments via animation displayed on the platform (see Figure 3(b)). After students completed each virtual experiment, a quiz was used to test their understanding of the learning content (see Figure 3(c)). Once the students submitted a quiz online, positive or negative feedback was shown. Students could thus selfevaluate their understanding of what they learned (see Figure 3(d)). 


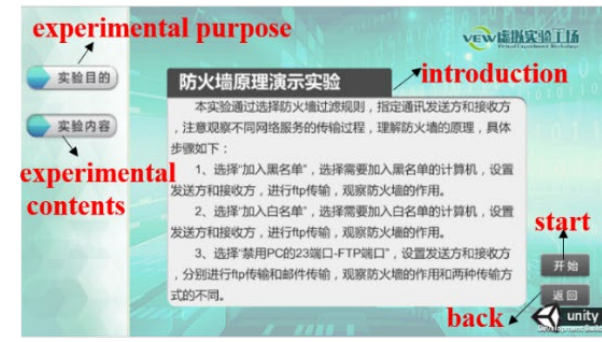

(a) Main menu

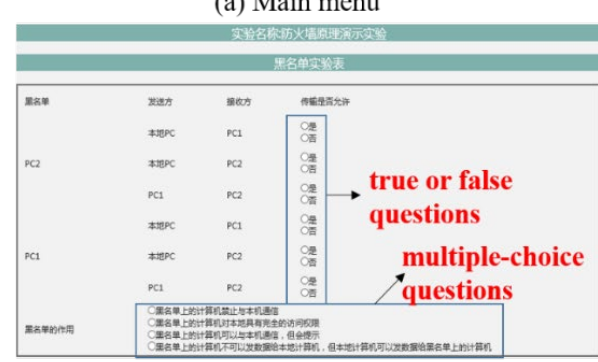

(c) The interface of the test

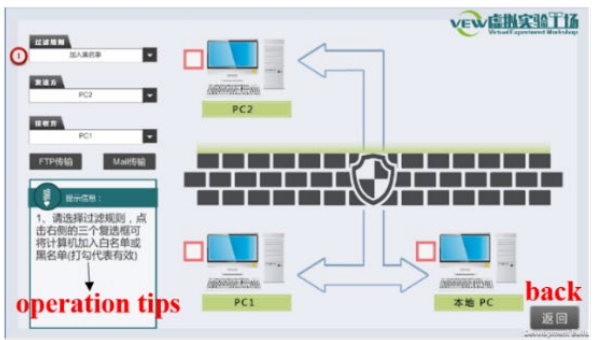

(b) The interface of the experiment

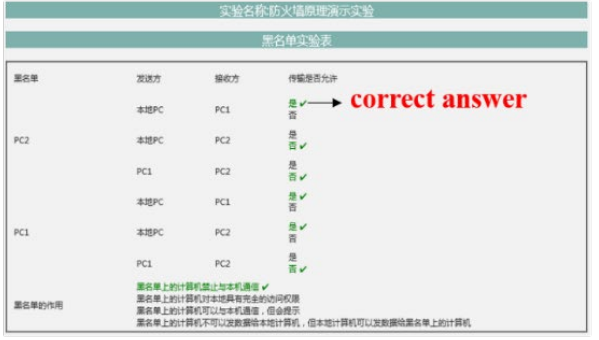

(d) The interface of the feedback

Figure 3. The interfaces of a virtual experiment

\section{Data analysis}

We adopted a structural equation modelling approach to analyse the data, which consisted of two steps. First, we performed a confirmatory factor analysis assessing construct validity and reliability of the instrument to examine the measurement model. Second, we carried out path analysis to evaluate the relationship between the latent variables in the structural model. We employed SPSS AMOS 22.0 and SPSS 19.0 to perform the above analyses. To meet the basic requirements of structural equation analysis, the normal distribution of sample data was examined by skewness and kurtosis values; the results met the demand of a multivariate normal distribution in that the values of skewness were no more than 3 and the kurtosis values were no more than 10 (Kline, 2011), thus showing the sample data to be normally distributed.

\section{Results}

\section{Sample demographics}

Table 3 shows the demographic profile of the sample. The total number of students surveyed was 240 , of whom 238 students reported back, resulting in a 99\% response rate.

Table 3

Demographic profile of the sample

\begin{tabular}{llcc}
\hline Profile & Category & Number $(\boldsymbol{n})$ & Percentage (\%) \\
\hline Gender & Female & 87 & 36.55 \\
& Male & 151 & 63.45 \\
& 17 & 18 & 7.56 \\
& 18 & 122 & 51.26 \\
& 19 & 59 & 24.79 \\
& 20 & 28 & 11.76 \\
\multirow{4}{*}{ Major } & 21 & 11 & 4.62 \\
& Mechanical Engineering & 78 & 32.77 \\
& Electrical Engineering \& Automation & 59 & 24.79 \\
& Optoelectronic Information Science & 40 & 16.81 \\
& Information \& Computing Science & 24 & 10.08 \\
& Energy Engineering & 22 & 9.24 \\
& Nuclear Engineering & 15 & 6.30 \\
\hline
\end{tabular}

Note. $n=238$ 


\section{The measurement model}

This study examined the measurement model consisting of convergent validity, internal consistency reliability, and discriminant validity. Convergent validity deals with whether the survey constructs are well reflected by the measured items on the survey questionnaire (Tsai, Ho, Liang, \& Lin, 2011). According to Fornell and Larcker (1981), factor loadings, composite reliability (CR), and average variance extracted (AVE) are employed to examine the convergent validity of the survey questionnaire. As shown in Table 4, the loading values of all the measured items were significantly larger than 0.7 , exceeding the cut-off value of 0.5 . The CR ranged from 0.80 to 0.92 , exceeding the cut-off value of 0.7. In addition, the AVE ranged from 0.66 to 0.79 , exceeding the cut-off value of 0.5 . All multi-item constructs had to align with the guidelines with a composite reliability value higher than 0.70 and a Cronbach's alpha value above 0.70 (Hair, Anderson, Tatham, \& Black, 1998). Our result revealed that the Cronbach's alpha value for each construct was between 0.78 and 0.91 , while the overall alpha value was 0.95 , which indicates that the internal consistency of the instrument was sufficient. Considering these results, evidence of excellent reliability and convergent validity of the instrument was obtained in our study.

Table 4

Construct reliability and convergent validity

\begin{tabular}{|c|c|c|c|c|c|c|c|}
\hline Construct & $M$ & $S D$ & Loadings & $t$ value & AVE & CR & $\begin{array}{l}\text { Alpha } \\
\text { value }\end{array}$ \\
\hline Time distortion (TD) & 3.51 & 0.79 & & & 0.68 & 0.81 & 0.80 \\
\hline TD1 & & & 0.82 & - $^{\mathrm{a}}$ & & & \\
\hline TD2 & & & 0.83 & $8.92^{* * *}$ & & & \\
\hline Focused attention (FA) & 3.78 & 0.72 & & & 0.67 & 0.80 & 0.78 \\
\hline FA1 & & & 0.83 & - $^{\mathrm{a}}$ & & & \\
\hline FA2 & & & 0.82 & $12.04^{* * *}$ & & & \\
\hline Perceived usefulness (PU) & 3.85 & 0.68 & & & 0.70 & 0.88 & 0.86 \\
\hline PU1 & & & 0.83 & - $^{\mathrm{a}}$ & & & \\
\hline PU2 & & & 0.84 & $15.30^{* * *}$ & & & \\
\hline PU3 & & & 0.84 & $15.25^{* * *}$ & & & \\
\hline Confirmation $(\mathrm{C})$ & 3.64 & 0.70 & & & 0.66 & 0.85 & 0.84 \\
\hline $\mathrm{C} 1$ & & & 0.78 & $-^{\mathrm{a}}$ & & & \\
\hline $\mathrm{C} 2$ & & & 0.84 & $14.25^{* * *}$ & & & \\
\hline $\mathrm{C} 3$ & & & 0.82 & $13.80^{* * *}$ & & & \\
\hline Satisfaction (S) & 3.61 & 0.74 & & & 0.72 & 0.88 & 0.87 \\
\hline S1 & & & 0.83 & $-^{\mathrm{a}}$ & & & \\
\hline $\mathrm{S} 2$ & & & 0.86 & $16.28^{* * *}$ & & & \\
\hline S3 & & & 0.84 & $15.87^{* * *}$ & & & \\
\hline $\begin{array}{l}\text { Intention to continue using } \\
\text { (ICU) }\end{array}$ & 3.66 & 0.79 & & & 0.79 & 0.92 & 0.91 \\
\hline ICU 1 & & & 0.85 & - $^{a}$ & & & \\
\hline ICU 2 & & & 0.91 & $18.84^{* * *}$ & & & \\
\hline ICU 3 & & & 0.91 & $18.80^{* * *}$ & & & \\
\hline
\end{tabular}

Discriminant validity addresses whether survey constructs are independent of each other (Tsai et al., 2011). We followed the criteria proposed by Fornell and Larcker (1981), which state that the square root of the AVE of each construct should be larger than the cross-correlations between each construct and the others in the model and not less than 0.50. Table 5 shows that the square root of the AVE of the six constructs was between 0.81 and 0.89 , exceeding the cut-off value of 0.5. Furthermore, the square root of the AVE of each construct was larger than the correlation coefficients between each construct. The results thereby reveal that the discriminant validity of the instrument was quite acceptable. 
Table 5

Correlation and discriminant validity

\begin{tabular}{|c|c|c|c|c|c|c|}
\hline Construct & 1 & 2 & 3 & 4 & 5 & 6 \\
\hline 1 Time distortion & 0.82 & & & & & \\
\hline 2 Focused attention & $0.37^{* *}$ & 0.82 & & & & \\
\hline 3 Perceived usefulness & $0.41^{* *}$ & $0.55^{* *}$ & 0.84 & & & \\
\hline 4 Confirmation & $0.40^{* *}$ & $0.59^{* *}$ & $0.75^{* *}$ & 0.81 & & \\
\hline 5 Satisfaction & $0.38^{* *}$ & $0.61^{* *}$ & $0.70^{* *}$ & $0.80^{* *}$ & 0.85 & \\
\hline 6 Intention to continue using & $0.41^{* *}$ & $0.58^{* *}$ & $0.73^{* *}$ & $0.74^{* *}$ & $0.80^{* *}$ & 0.89 \\
\hline
\end{tabular}

Note. The square root of AVE are elements (in bold and italics) on the diagonal. The correlations among constructs were elements off the diagonal. ${ }^{* *} p<.01$

\section{The structural model and hypotheses testing}

The generally accepted rules for assessing the structural model (Anderson \& Gerbing, 1988; Bagozzi, Yi, \& Phillips, 1991) need to be met, such as a goodness-of-fit index (GFI) larger than 0.90; an adjusted GFI (AGFI) larger than 0.80; an incremental fix index (IFI) greater than 0.90; a comparative fit index (CFI) greater than 0.90; a Tucker-Lewis index (TLI) greater than 0.90; a root mean square error of approximation (RMSEA) less than 0.08 , and a value of $\chi^{2} / d f$ less than 3 . The results of the goodness-of-fit statistics of the structural model were as follows: $\chi^{2}=171.230, d f=97, \chi^{2} / d f=1.765, p<.001$, GFI $=0.918$, AGFI $=$ $0.885, \mathrm{CFI}=0.975, \mathrm{IFI}=0.975, \mathrm{TLI}=0.969$, and $\mathrm{RMSEA}=0.057$. Therefore, these results indicate the quite acceptable fit indices for the proposed model.

Figure 4 shows the results of the path analysis for testing each hypothesis, and Table 6 shows a summary of the hypothesis tests. Six out of the 13 hypotheses were supported with significant path coefficient values. The explained variances $\left(R^{2}\right)$ of intentions to continue using, confirmation, perceived usefulness, and satisfaction were $0.824,0.644,0.816$, and 0.889 , respectively. Confirmation had a positive effect on perceived usefulness $(\beta=0.90, p<.001)$ and satisfaction $(\beta=0.94, p<.001)$, indicating that $\mathrm{H} 1$ and $\mathrm{H} 2$ were supported. There was no significant relationship between perceived usefulness and satisfaction, indicating $\mathrm{H} 3$ was rejected. Perceived usefulness $(\beta=0.28, p<.01)$ and satisfaction $(\beta=0.66, p<.001)$ had significant effects on students' intentions to continue using VRLs, indicating that H4 and H5 were supported. Time distortion had a significant positive impact on confirmation $(\beta=0.20, p<.01)$, indicating H6a was supported. However, time distortion had an insignificant influence on satisfaction, perceived usefulness, and intention to continue using, indicating that H7a, H8a, and H9a were rejected. Focused attention had a positive influence on confirmation $(\beta=0.68, p<.001)$, but had no significant effect on satisfaction, perceived usefulness, or intention to continue using, indicating that H6b was supported while $\mathrm{H} 7 \mathrm{~b}, \mathrm{H} 8 \mathrm{~b}$, and $\mathrm{H} 9 \mathrm{~b}$ were rejected.

Table 6

Summary of hypothesis tests

\begin{tabular}{lllrc}
\hline Hypothesis & Path & $\boldsymbol{\beta}$ & $\boldsymbol{t}$ value & $\begin{array}{c}\text { Support } \\
\text { (Yes/No) }\end{array}$ \\
\hline H1 & Confirmation $\rightarrow$ Perceived usefulness & $0.90^{* * *}$ & 12.52 & Yes \\
H2 & Confirmation $\rightarrow$ Satisfaction & $0.94^{* * *}$ & 13.20 & Yes \\
H3 & Perceived usefulness $\rightarrow$ Satisfaction & 0.05 & 0.30 & No \\
H4 & Perceived usefulness $\rightarrow$ Intention to continue using & $0.28^{* *}$ & 2.79 & Yes \\
H5 & Satisfaction $\rightarrow$ Intention to continue using & $0.66^{* * *}$ & 6.34 & Yes \\
H6a & Time distortion $\rightarrow$ Confirmation & $0.20^{* *}$ & 2.82 & Yes \\
H6b & Focused attention $\rightarrow$ Confirmation & $0.68^{* * *}$ & 7.99 & Yes \\
H7a & Time distortion $\rightarrow$ Perceived usefulness & 0.09 & 1.38 & No \\
H7b & Focused attention $\rightarrow$ Perceived usefulness & 0.06 & 0.63 & No \\
H8a & Time distortion $\rightarrow$ Satisfaction & 0.01 & 0.17 & No \\
H8b & Focused attention $\rightarrow$ Satisfaction & 0.14 & 1.70 & No \\
H9a & Time distortion $\rightarrow$ Intention to continue using & 0.07 & 1.31 & No \\
H9b & Focused attention $\rightarrow$ Intention to continue using & 0.04 & 0.05 & No \\
\hline Note. ${ }^{* *} p<.01 ;{ }^{* * *} p<.001$ & & &
\end{tabular}




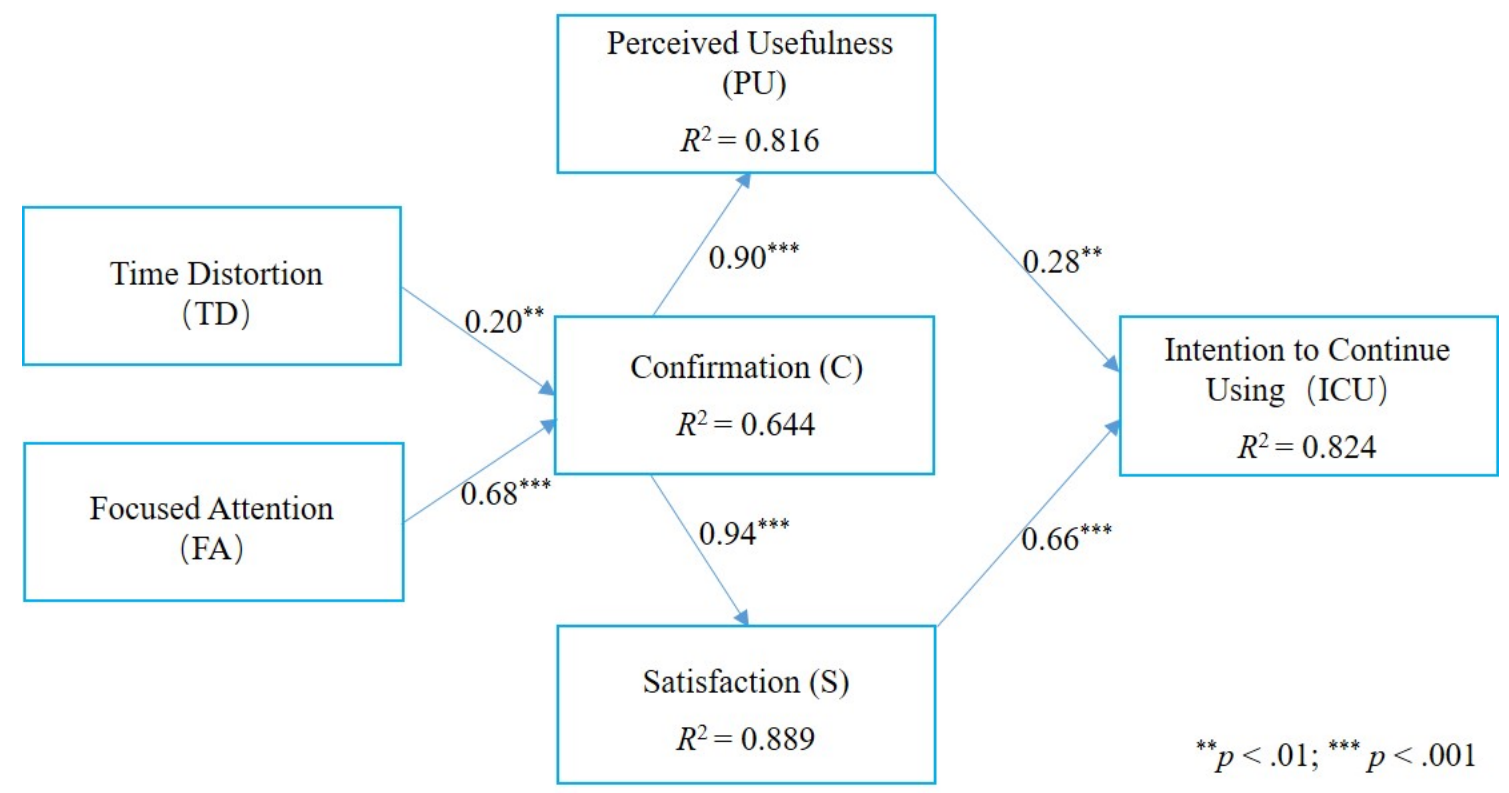

Figure 4. Results of testing the hypotheses

\section{Discussion and implications}

In this study, we put forward an integrated model that considered Bhattacherjee's (2001) ECM constructs and two other relevant variables (time distortion and focused attention) involving flow experience to help understand the intention to continue using VRLs. According to the findings, satisfaction was the strongest predictor, and perceived usefulness was a weaker predictor of students' intention to continue to use VRLs. Our findings are consistent with some previous studies, for example, that of Joo et al., (2017), who found that satisfaction was the biggest influencing factor for students' continuance intention to use digital textbooks, followed by perceived usefulness. As well, in the studies of Dağhan and Akkoyunlu (2016) and Alraimi et al. (2015), satisfaction was identified as having a significant impact on students' intention towards the continued use of a specific online course and/or MOOC. Based on our findings, we suggest that instructors or institutions should pay more attention to improving students' satisfaction with VRLbased experimental teaching. For example, students' satisfaction could be improved by eliminating students' isolation in the VRL experience (Mateo Sanguino, Fernández de Viana González, Cortés Ancos, \& Espejo Fernández, 2018) by enhancing the involvement of the instructors and improving the quality of VRLs (Viegas et al., 2018). Moreover, according to our study, perceived usefulness had no significant impact on satisfaction. This finding is inconsistent with the assumptions of the original ECM (Bhattacherjee, 2001). Nevertheless, in later studies, Bhattacherjee, Perols, and Sanford (2008) and Bhattacherjee and Lin (2015) claimed that there was an insignificant relationship between perceived usefulness and satisfaction. There is still no consensus on the definition of the ECM that presumes that satisfaction is significantly associated with perceived usefulness (Cheng, 2014b; Estriegana et al., 2019; Joo et al., 2017; Lee, 2010). In future studies, more effort is needed to elucidate the correlation between the two constructs. On the other hand, according to our study, confirmation positively affected students' satisfaction with and their perceived usefulness of using VRLs, which has also been confirmed in previous studies on e-learning (Alraimi et al., 2015; Cheng, 2014b; Ho, 2010; Lee, 2010). Our finding suggests that it was worth exploring the factors influencing students' confirmation of their expectations when using VRLs.

Considering the impact of time distortion and focused attention on confirmation, the findings reveal that students' experiences of flow had a positive effect on their confirmation of VRLs. However, according to our study, flow experience had no effect on perceived usefulness, satisfaction, or intention to continue to use VRLs. There is still no consensus on flow as a determinant of satisfaction and intention to continue to use (Buil et al., 2018; Cheng, 2014a; Hong et al., 2019; Shin, 2006) or that flow is an indirect mediator influencing satisfaction and intention to continue using (Guo et al., 2016; Kang \& Kim, 2018; RodríguezArdura \& Meseguer-Artola, 2016). Despite this lack of consensus, we suggest that instructors or institutions could enhance the extent of students' confirmation of their expectations of VRLs by providing them with 
optimal flow experiences. In that way, students' satisfaction with VRLs learning would be improved, ensuring their intention to continue to use VRLs. Creating a high-interaction scenario between students and the virtual environment to inspire or strengthen their flow experience in VRLs is critical (Rodríguez-Ardura \& Meseguer-Artola, 2016). Some challenge mechanism embedded into VRLs, such as gamification (Chang et al., 2018) or simulation with human-computer interaction environments (Wang \& Hsu, 2014), may improve students' flow experiences. Gamification or game-based learning designed in digital learning contexts could help to increase student engagement (Ronimus, Kujala, Tolvanen, \& Lyytinen, 2014), facilitate flow experience (Kiili, 2005), and enhance student enjoyment, leading to satisfaction (Brom et al., 2014). Some human-computer interaction environments could also enable learners to immerse themselves in learning subjects (Hodges, Wang, Lee, Cohen, \& Jang, 2018) and obtain a better learning experience (Moro et al., 2017). For example, the adoption of some advanced technologies, such as augmented reality (Ibáñez, Di Serio, Villarán, \& Delgado Kloos, 2014), might inspire students to reach higher flow experience levels.

\section{Contributions and limitations}

We integrated the ECM and flow theory (time distortion and focused attention) to explore the potential relationships among the factors associated with university students' intention to continue to use VRLs. As expected, satisfaction was the most crucial determinant of the students' intention to continue using VRLs, followed closely by perceived usefulness. Confirmation had an indirect impact on students' intention to continue to use VRLs through satisfaction and perceived usefulness. We also confirmed that both time distortion and focused attention positively affect students' confirmation of expectations of VRLs use. As emphasised by Lee (2010), what factors affect confirmation and how they can be manipulated are areas of future research, since confirmation is a critical antecedent to satisfaction. This study has enriched scholarly understanding of university students' experiences with VRLs. Students' perceptions of using VRLs, especially their satisfaction and intention to continue to use, are essential for further understanding the application of online learning in engineering and science education. As Potkonjak et al. (2016) have pointed out, it is promising that there is extensive use of VRLs applications in engineering or scientific education due to the continued technological progress in virtual reality, computer graphics, and the virtual world. Overall, there are several contributions of this study. First, this study extends previous literature by integrating the ECM and flow theory to explain and predict students' satisfaction and intention to continue to use VRLs. Thus, the findings extend our knowledge of the significant positive relationship between flow experiences and confirmation. Second, this study may help designers, instructors, and higher education institutions to consider how to design a better VRL environment to bring about a better learning experience for students.

Although some interesting findings have been presented, there are some limitations to this study. First, all participants were undergraduate students from one university in China. Due to the limitations of the sample, the aforementioned results cannot be generalised to university students in other countries. Second, given our research context, only two indicators (time distortion and focused attention) were selected to investigate the students' flow experiences. Other variables related to flow experiences need to be included to allow for a more extensive discussion in future studies. Finally, we adopted only the virtual lab Virtual Experiment Workshop, developed by the Beijing Institute of Technology, in our study. Other types of VRLs equipped with virtual reality, augmented reality, and virtual worlds could be adopted and compared in future research.

\section{Acknowledgments}

This research work is supported by the National Natural Science Foundation of China (Grant No: 61877003), the Philosophy and Social Sciences Planning Project of Zhejiang Province (Grant No: 18NDJC026Z), and the International Joint Research Project of Faculty of Education of Beijing Normal University. 


\section{References}

Ajzen, I. (1991). The theory of planned behavior. Organizational Behavior and Human Decision Processes, 50, 179-211. https://doi.org/10.1016/0749-5978(91)90020-T

Alraimi, K. M., Zo, H., \& Ciganek, A. P. (2015). Understanding the MOOCs continuance: The role of openness and reputation. Computers \& Education, 80, 28-38. https://doi.org/10.1016/j.compedu.2014.08.006

Alves, G., Viegas, C., Lima, N., \& Gustavsson, I. (2016). Simultaneous usage of methods for the development of experimental competences. International Journal of Human Capital and Information Technology Professionals, 7(1), 48-65. https://doi.org/10.4018/IJHCITP.2016010104

Ambalov, I. A. (2018). A meta-analysis of it continuance: An evaluation of the expectation-confirmation model. Telematics and Informatics, 35(6), 1561-1571. https://doi.org/10.1016/j.tele.2018.03.016

Anderson, J. C., \& Gerbing, D. W. (1988). Structural equation modeling in practice: A review and recommended two-step approach. Psychological Bulletin, 103(3), 411-423. https://doi.org/10.1037/0033-2909.103.3.411

Bagozzi, R. P., Yi, Y., \& Phillips, L. W. (1991). Assessing construct validity in organizational research. Administrative Science Quarterly, 36(3), 421-458. https://doi.org/10.2307/2393203

Baker-Eveleth, L., \& Stone, R. W. (2015). Usability, expectation, confirmation, and continuance intentions to use electronic textbooks. Behaviour \& Information Technology, 34(10), 992-1004. https://doi.org/10.1080/0144929X.2015.1039061

Barbeau, M. L., Johnson, M., Gibson, C., \& Rogers, K. A. (2013). The development and assessment of an online microscopic anatomy laboratory course. Anatomical Sciences Education, 6(4), 246-256. https://doi.org/10.1002/ase.1347

Bhattacherjee, A. (2001). Understanding information systems continuance: An expectation-confirmation model. MIS Quarterly, 25(3), 351-370. https://doi.org/10.2307/3250921

Bhattacherjee, A., \& Lin, C.-P. (2015). A unified model of IT continuance: Three complementary perspectives and crossover effects. European Journal of Information Systems, 24(4), 364-373. https://doi.org/10.1057/ejis.2013.36

Bhattacherjee, A., Perols, J., \& Sanford, C. (2008). Information technology continuance: A theoretic extension and empirical test. Journal of Computer Information Systems, 49(1), 17-26. https://doi.org/10.1080/08874417.2008.11645302

Birt, J., Stromberga, Z., Cowling, M., \& Moro, C. (2018). Mobile mixed reality for experiential learning and simulation in medical and health sciences education. Information (Switzerland), 9(2), 1-14. https://doi.org/10.3390/info9020031

Brinson, J. R. (2015). Learning outcome achievement in non-traditional (virtual and remote) versus traditional (hands-on) laboratories: A review of the empirical research. Computers \& Education, 87, 218-237. https://doi.org/10.1016/j.compedu.2015.07.003

Brom, C., Buchtová, M., Šisler, V., Děchtěrenko, F., Palme, R., \& Glenk, L. M. (2014). Flow, social interaction anxiety and salivary cortisol responses in serious games: A quasi-experimental study. Computers and Education, 79, 69-100. https://doi.org/10.1016/j.compedu.2014.07.001

Buil, I., Catalán, S., \& Martínez, E. (2018). Exploring students' flow experiences in business simulation games. Journal of Computer Assisted Learning, 34(2), 183-192. https://doi.org/10.1111/jcal.12237

Chang, C. C., Warden, C. A., Liang, C., \& Lin, G. Y. (2018). Effects of digital game-based learning on achievement, flow and overall cognitive load. Australasian Journal of Educational Technology, 34(4), 155-167. https://doi.org/10.14742/ajet.2961

Chao, J., Chiu, J. L., DeJaegher, C. J., \& Pan, E. A. (2016). Sensor-augmented virtual labs: Using physical interactions with science simulations to promote understanding of gas behavior. Journal of Science Education and Technology, 25(1), 16-33. https://doi.org/10.1007/s10956-015-9574-4

Chen, H., Wigand, R. T., \& Nilan, M. (2000). Exploring web users' optimal flow experiences. Information Technology \& People, 13(4), 263-281. https://doi.org/10.1108/09593840010359473

Cheng, Y.-M. (2014a). Extending the expectation-confirmation model with quality and flow to explore nurses' continued blended e-learning intention. Information Technology \& People, 27(3), 230-258. https://doi.org/10.1108/ITP-01-2013-0024

Cheng, Y.-M. (2014b). What drives nurses' blended e-learning continuance intention? Journal of Educational Technology \& Society, 17(4), 203-215. Retrieved from https://www.jstor.org/stable/jeductechsoci.17.4.203

Csikszentmihalyi, M. (1990). Flow: The psychology of optimal experience. New York, NY: Harper. 
Csikszentmihalyi, M. (2014). Applications of flow in human development and education: The collected work of Mihaly Csikszentmihalyi. Dordrecht, The Netherlands: Springer.

Dağhan, G., \& Akkoyunlu, B. (2016). Modeling the continuance usage intention of online learning environments. Computers in Human Behavior, 60, 198-211. https://doi.org/10.1016/j.chb.2016.02.066

Davis, F. D. (1989). Perceived usefulness, perceived ease of use, and user acceptance of information technology. MIS Quarterly, 13 (3), 319-340. https://doi.org/10.2307/249008

Deci, E. L., \& Ryan, R. M. (2000). The "what" and "why" of goal pursuits: Human needs and the selfdetermination of behavior. Psychological Inquiry, 11(4), 227-268. https://doi.org/10.1207/S15327965PLI110401

Esteban-Millat, I., Martínez-López, F. J., Huertas-García, R., Meseguer, A., \& Rodríguez-Ardura, I. (2014). Modelling students' flow experiences in an online learning environment. Computers \& Education, 71, 111-123. https://doi.org/10.1016/j.compedu.2013.09.012

Estriegana, R., Medina-Merodio, J.-A., \& Barchino, R. (2019). Student acceptance of virtual laboratory and practical work: An extension of the technology acceptance model. Computers \& Education, 135, 1-14. https://doi.org/10.1016/j.compedu.2019.02.010

Faulconer, E. K., \& Gruss, A. B. (2018). A review to weigh the pros and cons of online, remote, and distance science laboratory experiences. The International Review of Research in Open and Distributed Learning, 19(2), 155-168. https://doi.org/10.19173/irrodl.v19i2.3386

Fornell, C., \& Larcker, D. F. (1981). Evaluating structural equation models with unobservable variables and measurement error. Journal of Marketing Research, 18(1), 39-50. https://doi.org/10.2307/3151312

Grodotzki, J., Ortelt, T. R., \& Tekkaya, A. E. (2018). Remote and virtual labs for engineering education 4.0. Procedia Manufacturing, 26, 1349-1360. https://doi.org/10.1016/j.promfg.2018.07.126

Guo, Z., Xiao, L., Van Toorn, C., Lai, Y., \& Seo, C. (2016). Promoting online learners' continuance intention: An integrated flow framework. Information and Management, 53(2), 279-295. https://doi.org/10.1016/j.im.2015.10.010

Hair, J. F., Anderson, R. E., Tatham, R. L., \& Black, W. C. (1998). Multivariate data analysis: With readings (5th ed.). Englewood Cliffs, NJ: Prentice-Hall.

Halilovic, S., \& Cicic, M. (2013). Understanding determinants of information systems users' behaviour: A comparison of two models in the context of integrated accounting and budgeting software. Behaviour \& Information Technology, 32(12), 1280-1291. https://doi.org/10.1080/0144929X.2012.708784

Hawkins, I., \& Phelps, A. J. (2013). Virtual laboratory vs. traditional laboratory: Which is more effective for teaching electrochemistry? Chemistry Education Research and Practice, 14(4), 516-523. https://doi.org/10.1039/C3RP00070B

Heradio, R., De La Torre, L., Galan, D., Cabrerizo, F. J., Herrera-Viedma, E., \& Dormido, S. (2016). Virtual and remote labs in education: A bibliometric analysis. Computers \& Education, 98, 14-38. https://doi.org/10.1016/j.compedu.2016.03.010

Ho, C.-H. (2010). Continuance intention of e-learning platform: Toward an integrated model. International Journal of Electronic Business Management, 8(3), 206-215. Retrieved from http://www.oalib.com/paper/2070675

Hodges, G. W., Wang, L., Lee, J., Cohen, A., \& Jang, Y. (2018). An exploratory study of blending the virtual world and the laboratory experience in secondary chemistry classrooms. Computers \& Education, 122, 179-193. https://doi.org/10.1016/j.compedu.2018.03.003

Hoffman, D. L., \& Novak, T. P. (1996). Marketing in hypermedia computer-mediated environments: Conceptual foundations. Journal of Marketing, 60(3), 50-68. https://doi.org/10.2307/1251841

Hong, J.-C., Tsai, C.-R., Hsiao, H.-S., Chen, P.-H., Chu, K.-C., Gu, J., \& Sitthiworachart, J. (2019). The effect of the "prediction-observation-quiz-explanation" inquiry-based e-learning model on flow experience in green energy learning. Computers \& Education, 133(4), 127-138. https://doi.org/10.1016/j.compedu.2019.01.009

Ibáñez, M. B., Di Serio, Á., Villarán, D., \& Delgado Kloos, C. (2014). Experimenting with electromagnetism using augmented reality: Impact on flow student experience and educational effectiveness. Computers \& Education, 71, 1-13. https://doi.org/10.1016/j.compedu.2013.09.004

Joo, S., \& Choi, N. (2016). Understanding users' continuance intention to use online library resources based on an extended expectation-confirmation model. Electronic Library, 34(4), 554-571. https://doi.org/10.1108/EL-02-2015-0033 
Joo, Y., Lim, K. Y., \& Kim, S. M. (2012). A model for predicting learning flow and achievement in corporate e- learning. Educational Technology and Society, 15(1), 313-325. Retrieved from https://www.jstor.org/stable/jeductechsoci.15.1.313

Joo, Y., Park, S., \& Shin, E. K. (2017). Students' expectation, satisfaction, and continuance intention to use digital textbooks. Computers in Human Behavior, 69, 83-90. https://doi.org/10.1016/j.chb.2016.12.025

Kang, K.-S., \& Kim, H.-C. (2018). Testing the mediating effects of flow in the structural relationship among contents quality, telepresence, and continuous intention to use e-learning services. E-Trade Review, 16(1), 19-40. https://doi.org/10.17255/etr.16.1.201802.19

Kiili, K. (2005). Digital game-based learning: Towards an experiential gaming model. The Internet and Higher Education, 8(1), 13-24. https://doi.org/10.1016/j.iheduc.2004.12.001

Kim, H. W., Chan, H. C., \& Chan, Y. P. (2007). A balanced thinking-feelings model of information systems continuance. International Journal of Human-Computer Studies, 65, 511-525. https://doi.org/10.1016/j.ijhcs.2006.11.009

Kline, R. B. (2011). Principles and practice of structural equation modeling (3rd ed.). New York, NY: The Guilford Press.

Lang, J. (2012). Comparative study of hands-on and remote physics labs for first year university level physics students. Transformative Dialogues: Teaching \& Learning Journal, 6(1), 1-25. Retrieved from

https://www.kpu.ca/sites/default/files/Teaching\%20and\%20Learning/TD.6.1.2 Lang Comparative St udy_of_Physics_Labs.pdf

Liao, C., Palvia, P., \& Chen, J.-L. (2009). Information technology adoption behavior life cycle: Toward a technology continuance theory (TCT). International Journal of Information Management, 29(4), 309320. https://doi.org/10.1016/j.ijinfomgt.2009.03.004

Lee, M. C. (2010). Explaining and predicting users' continuance intention toward e-learning: An extension of the expectation-confirmation model. Computers \& Education, 54(2), 506-516. https://doi.org/10.1016/j.compedu.2009.09.002

Leung, L., \& Chen, C. (2019). E-health/m-health adoption and lifestyle improvements: Exploring the roles of technology readiness, the expectation-confirmation model, and health-related information activities. Telecommunications Policy, 43(6), 563-575. https://doi.org/10.1016/j.telpol.2019.01.005

Liu, N., Yang, X., \& Chan, H. C. (2013). Exploring the antecedents to learning continuance in virtual worlds. Journal of Global Information Management, 21(2), 1-22. https://doi.org/10.4018/jgim.2013040101

Makransky, G., Terkildsen, T. S., \& Mayer, R. E. (2019). Adding immersive virtual reality to a science lab simulation causes more presence but less learning. Learning and Instruction, 60, 225-236. https://doi.org/10.1016/j.learninstruc.2017.12.007

Malik, G., \& Rao, A. S. (2019). Extended expectation-confirmation model to predict continued usage of ODR/ride hailing apps: Role of perceived value and self-efficacy. Information Technology \& Tourism, 21(4), 461-482. https://doi.org/10.1007/s40558-019-00152-3

Mateo Sanguino, T. de J., Fernández de Viana González, I. J., Cortés Ancos, E., \& Espejo Fernández, J. (2018). Exploring strengths and weaknesses: A case study after developing a remote network lab. Computer Applications in Engineering Education, 26(5), 1422-1434. https://doi.org/10.1002/cae.21981

Matute-Vallejo, J., \& Melero-Polo, I. (2019). Understanding online business simulation games: The role of flow experience, perceived enjoyment and personal innovativeness. Australasian Journal of Educational Technology, 35(3), 71-85. https://doi.org/10.14742/ajet.3862

Moro, C., Stromberga, Z., \& Stirling, A. (2017). Virtualisation devices for student learning: Comparison between desktop-based (Oculus Rift) and mobile-based (Gear VR) virtual reality in medical and health science education. Australasian Journal of Educational Technology, 33(6), 1-10. https://doi.org/10.14742/ajet.3840

Nolen, S. B., \& Koretsky, M. D. (2018). Affordances of virtual and physical laboratory projects for instructional design: Impacts on student engagement. IEEE Transactions on Education, 61(3), 226233. https://doi.org/10.1109/TE.2018.2791445

Novak, T. P., Hoffman, D. L., \& Yung, Y.-F. (2000). Measuring the customer experience in online environments: A structural modeling approach. Marketing Science, 19(1), 22-42. https://doi.org/10.1287/mksc. 19.1.22.15184

Oliver, R. L. (1980). A cognitive model of the antecedents and consequences of satisfaction decisions. Journal of Marketing Research, 17(4), 460-469. https://doi.org/10.2307/3150499 
Post, L. S., Guo, P., Saab, N., \& Admiraal, W. (2019). Effects of remote labs on cognitive, behavioral, and affective learning outcomes in higher education. Computers \& Education, 140, 1-9. https://doi.org/10.1016/j.compedu.2019.103596

Potkonjak, V., Gardner, M., Callaghan, V., Mattila, P., Guetl, C., Petrović, V. M., \& Jovanović, K. (2016). Virtual laboratories for education in science, technology, and engineering: A review. Computers \& Education, 95, 309-327. https://doi.org/10.1016/j.compedu.2016.02.002

Pyatt, K., \& Sims, R. (2012). Virtual and physical experimentation in inquiry-based science labs: Attitudes, performance and access. Journal of Science Education and Technology, 21(1), 133-147. https://doi.org/10.1007/s10956-011-9291-6

Qian, M., \& Clark, K. R. (2016). Game-based Learning and 21st century skills: A review of recent research. Computers in Human Behavior, 63, 50-58. https://doi.org/10.1016/j.chb.2016.05.023

Raman, R., Achuthan, K., Nedungadi, P., Diwakar, S., \& Bose, R. (2014). The VLAB OER experience: Modeling potential-adopter student acceptance. IEEE Transactions on Education, 57(4), 235-241. https://doi.org/10.1109/TE.2013.2294152

Rodríguez-Ardura, I., \& Meseguer-Artola, A. (2016). E-learning continuance: The impact of interactivity and the mediating role of imagery, presence and flow. Information and Management, 53(4), 504-516. https://doi.org/10.1016/j.im.2015.11.005

Rogers, E. M. (2003). Diffusion of innovations (5th ed.). New York, NY: Free Press.

Ronimus, M., Kujala, J., Tolvanen, A., \& Lyytinen, H. (2014). Children's engagement during digital game-based learning of reading: The effects of time, rewards, and challenge. Computers \& Education, 71, 237-246. https://doi.org/10.1016/j.compedu.2013.10.008

Shin, N. (2006). Online learner's "flow" experience: An empirical study. British Journal of Educational Technology, 37(5), 705-720. https://doi.org/10.1111/j.1467-8535.2006.00641.x

Skadberg, Y. X., \& Kimmel, J. R. (2004). Visitors' flow experience while browsing a web site: Its measurement, contributing factors and consequences. Computers in Human Behavior, 20(3), 403-422. https://doi.org/10.1016/S0747-5632(03)00050-5

Tatli, Z., \& Ayas, A. (2013). Effect of a virtual chemistry laboratory on students' achievement. Educational Technology \& Society, 16(1), 159-170. Retrieved from http://www.ifets.info/journals/16 1/14.pdf

Teng, M., Nedic, Z., \& Nafalski, A. (2016). Students' perception of remote laboratories - Case study: NetLab. In Proceedings of the 2016 IEEE Global Engineering Education Conference (EDUCON) (pp. 568-575). IEEE Education Society. https://doi.org/10.1109/EDUCON.2016.7474608

Tho, S. W., \& Yeung, Y. Y. (2016). Technology-enhanced science learning through remote laboratory: System design and pilot implementation in tertiary education. Australasian Journal of Educational Technology, 32(3), 96-111. https://doi.org/10.14742/ajet.2203

Trevino, L. K., \& Webster, J. (1992). Flow in computer-mediated communication. Communication Research, 19(5), 539-573. https://doi.org/10.1177/009365092019005001

Tsai, C. C., Ho, H. N. J., Liang, J. C., \& Lin, H. M. (2011). Scientific epistemic beliefs, conceptions of learning science and self-efficacy of learning science among high school students. Learning and Instruction, 21(6), 757-769. https://doi.org/10.1016/j.learninstruc.2011.05.002

Viegas, C., Pavani, A., Lima, N., Marques, A., Pozzo, I., Dobboletta, E., ... Alves, G. (2018). Impact of a remote lab on teaching practices and student learning. Computers \& Education, 126, 201-216. https://doi.org/10.1016/j.compedu.2018.07.012

Vijay, T. S., Prashar, S., \& Gupta, S. (2018). Intention to provide online reviews: An expectation confirmation model with review involvement. Pacific Asia Journal of the Association for Information Systems, 10(2), 25-54. https://doi.org/10.17705/1pais.10202

Vrellis, I., Avouris, N., \& Mikropoulos, T. A. (2016). Learning outcome, presence and satisfaction from a science activity in Second Life. Australasian Journal of Educational Technology, 32(1), 59-77. https://doi.org/10.14742/ajet.2164

Vygotsky, L. S. (1986). Thought and language. Cambridge, MA: The MIT Press.

Wang, C. C., \& Hsu, M. C. (2014). An exploratory study using inexpensive electroencephalography (EEG) to understand flow experience in computer-based instruction. Information and Management, 51(7), 912-923. https://doi.org/10.1016/j.im.2014.05.010

Webster, J., Trevino, L. K., \& Ryan, L. (1993). The dimensionality and correlates of flow in humancomputer interactions. Computers in Human Behavior, 9(4), 411-426. https://doi.org/10.1016/07475632(93)90032-N 
Zhou, J. (2017). Exploring the factors affecting learners' continuance intention of moocs for online collaborative learning: An extended ECM perspective. Australasian Journal of Educational Technology, 33(5), 123-135. https://doi.org/10.14742/ajet.2914

Corresponding author: Chien-Yuan Su, bredysu@gmail.com

Copyright: Articles published in the Australasian Journal of Educational Technology (AJET) are available under Creative Commons Attribution Non-Commercial No Derivatives License (CC BY-NC-ND 4.0). Authors retain copyright in their work and grant AJET right of first publication under CC BY-NC-ND 4.0.

Please cite as: Zhang, M.-H., Su, C.-Y., Li, Y., Li, Y.-Y. (2020). Factors affecting Chinese university students' intention to continue using virtual and remote labs. Australasian Journal of Educational Technology, 36(2), 169-185. https://doi.org/10.14742/ajet.5939 